\title{
Antioxidation and Tyrosinase Inhibitory Ability of Coffee Pulp Extract by Ethanol
}

\author{
Cheng-You Chen, ${ }^{1}$ Chia-Hung Shih, ${ }^{2,3}$ Tzu-Che Lin, ${ }^{4}$ Ji-Hong Zheng, ${ }^{2}$ Chien-Chieh Hsu, ${ }^{5}$ \\ Kai-Meng Chen, ${ }^{2}$ Yung-Sheng Lin $\mathbb{D}^{1,2,6}$ and Chin-Tung $\mathrm{Wu} \mathbb{D}^{7}$ \\ ${ }^{1}$ Ph. D. Program in Materials and Chemical Engineering, National United University, Miaoli 360001, Taiwan \\ ${ }^{2}$ Department of Chemical Engineering, National United University, Miaoli 360001, Taiwan \\ ${ }^{3}$ Miaoli District Agricultural Research and Extension Station, Council of Agriculture, Miaoli 360001, Taiwan \\ ${ }^{4}$ Department of Plant Industry, National Pingtung University of Science and Technology, Pingtung 912301, Taiwan \\ ${ }^{5}$ Department of Bussiness Administration, College of Management, National Yunlin University of Science and Technology, \\ Yunlin 640301, Taiwan \\ ${ }^{6}$ Institute of Food Safety and Health Risk Assessment, National Yang Ming Chiao Tung University, Taipei 112304, Taiwan \\ ${ }^{7}$ Bachelor Program in Interdisciplinary Studies, College of Future, National Yunlin University of Science and Technology, \\ Yunlin 640301, Taiwan \\ Correspondence should be addressed to Yung-Sheng Lin; linys@nuu.edu.tw and Chin-Tung Wu; ctwu5@yuntech.edu.tw
}

Received 23 July 2021; Revised 22 November 2021; Accepted 1 December 2021; Published 17 December 2021

Academic Editor: Clara Cilindre

Copyright (C) 2021 Cheng-You Chen et al. This is an open access article distributed under the Creative Commons Attribution License, which permits unrestricted use, distribution, and reproduction in any medium, provided the original work is properly cited.

\begin{abstract}
Background. Following petroleum, coffee is the second most commonly traded commodity globally. It is also a popular good with economic value, as well as value in terms of leisure and culture. However, coffee processing generates a large amount of waste, resulting in environmental concerns. Therefore, in this study, ethanol was used to extract coffee waste (coffee pulp). Highperformance liquid chromatography was conducted to examine the caffeine content and chlorogenic acid content, and the antioxidant capacity (i.e., the total phenolic content, total flavonoid content, DPPH-free radical scavenging capacity, ABTS-free radical scavenging capacity, and reductive capacity) and the tyrosinase inhibition capacity of the coffee pulp extracted using ethanol were comprehensively evaluated. Results. The results showed that the coffee pulp extract obtained using $70 \%$ ethanol had the highest tyrosinase inhibition capacity, whereas that obtained using $50 \%$ ethanol had the most satisfactory antioxidant capacity (total phenolic content, total flavonoid content, DPPH-free radical scavenging capacity, ABTS-free radical scavenging capacity, and reductive capacity). Conclusion. The results revealed that coffee pulp has superior antioxidant capacity and tyrosinase inhibition capacity when extracted by ethanol. Increasing the economic value of coffee pulp can solve the environmental concerns caused by coffee waste.
\end{abstract}

\section{Introduction}

Coffee has many benefits for the body. It not only protects cells from damage [1] and cardiovascular diseases [2] but also reduces the risk of cancer [3]; therefore, coffee is an essential commodity and a popular beverage [4]. Currently, it is produced in approximately 60 tropical and subtropical countries and is exported as an agricultural product [5]. According to the data released by the International Coffee Organization, the global annual coffee consumption and production have gradually increased over the past 30 years, from 5.59 million tons in 1990 to 10.06 million tons in 2020 $[4,6]$, with an average growth rate of $18 \%-25 \%$ per 10 years. Twenty years ago, the global coffee consumption was more 
than 2.25 billion cups per day [7]. Currently, following petroleum, coffee has become the second most traded goods worldwide $[5,8]$. It is not only a beverage but also an essential factor for human beings with economic value, as well as value in terms of leisure and culture.

Coffee is a popular beverage, and its consumption has increased over the past 150 years [9]. However, the increasing demand for coffee has also indirectly caused environmental concerns [10]. During coffee processing, a large amount of waste, mainly pulp, is generated $[5,8]$. In addition, some coffee by-products are discarded during processing. The amount of by-product waste accounts for approximately $30 \%-50 \%$ of the total coffee weight depending on the type of coffee products produced [11]. In the past 30 years, the amount of coffee waste generated every year has exceeded 1 million tons [6], and the total amount has exceeded hundreds of millions of tons, which is a major issue in today's era where environmental protection is highly emphasized.

With the increase in environmental protection awareness, the recycling value of coffee by-product waste has been accentuated [12]. Coffee by-product waste, including coffee pulp, cherry husk, silver skin, and spent coffee, is conventionally prepared into feed or fertilizer [13]. However, the waste differs in terms of type, composition, and content. For developing their commercial value, different types of waste have been applied in different fields, such as food science [8], biological science [5, 14, 15], material science [16, 17], aquaculture [18], agriculture $[5,15]$, and environmental science $[19,20]$. Thus, coffee byproduct waste has multiple applications and high economic value.

Recently, antioxidants have substantial value in the fields of physiology, pharmacology, nutrition, and food processing [21]. They also serve as the main appeal of cosmetics and health supplements. Thus, they have great commercial value. In 2015, Barbulova et al. reported that more than 5 billion cosmetic products are sold every year, and the sales are not affected by world economic crises. The cosmetics market has shown robust growth. Coffee by-products are green, biosustainable, and inexpensive; therefore, they are suitable for cosmetics development [22]. However, studies have mostly examined the antioxidant capacity of spent coffee [23]; scant research has focused on the antioxidant capacity of coffee pulp.

Currently, the common extraction method for extracting coffee pulp is solvent extraction. Methanol is used as the main solvent [24-28], whereas ethyl acetate [26], isopropanol [13], acetone [25, 27], and hydrochloric acid [29] are used for extraction analysis. However, these solvents are unsafe for the human body. Surprisingly, few studies have used ethanol, a safer solvent, to extract coffee pulp; in addition, none of these studies have examined the capacity of coffee pulp for tyrosinase inhibition.

In this study, a literature review revealed that few studies have conducted a complete evaluation of the effect of ethanol-extracted coffee pulp on enhancing the antioxidant and tyrosinase inhibition capacity of cosmetic products. Therefore, in this study, the optimal condition for extracting coffee pulp by using ethanol was explored, and the coffee pulp's antioxidant and tyrosinase inhibition capacity was analyzed to increase its economic value and solve the environmental concerns caused by coffee waste.

\section{Materials and Methods}

2.1. Extraction of the Green Coffee by-Product. Coffee pulp by-products (Figure 1(a)) of the mature fruits of $C$. arabica L. (Arabica) was produced by wet processing. First, the hot air oven $\left(40^{\circ} \mathrm{C}\right)$ was used to reduce the moisture content of the coffee pulp until it reached a constant weight. Dry coffee pulp was ground into a fine powder (Figure 1(b)) by a mortar and pestle and then stored at $4^{\circ} \mathrm{C}$ before use. Subsequently, $0.5 \mathrm{~g}$ of coffee pulp powder was precisely weighed and placed into sample bottles, and $8 \mathrm{~mL}$ of solvent $(0 \%, 50 \%, 70 \%$, and $99.5 \%$ ethanol) was added. The solutions were treated in an ultrasonicator at $30^{\circ} \mathrm{C}$ for 15 minutes, and the extract was sucked into a centrifuge tube. After the extract was centrifuged at $3000 \mathrm{rpm}$ for 10 minutes, the supernatant was collected and filtered through a $0.45-\mu \mathrm{m}$ syringe filter, and the by-product extract was obtained. Figure 1(c) reveals that the coffee pulp extracts obtained using different ethanol concentrations have different colors. The color changes from reddish brown to light yellow with an increase in the ethanol concentration, which indicates that a higher ethanol concentration results in a lighter extract color.

\subsection{Content Analysis through High-Performance Liquid Chromatography}

2.2.1. Caffeine Content Analysis. According to the optimized and validated method in a high-performance liquid chromatography (HPLC) [30], caffeine content analysis was conducted on a HPLC instrument (LC-20AT, Shimadzu, Japan) equipped with an ultraviolet-visible detector (SPD20A, Shimadzu). The applied separation column was the Enduro C18G, $125 \AA$, $5 \mu \mathrm{m}, 250 \times 4.6 \mathrm{~mm}$ column (SGE, Australia). Deionized water and methanol were mixed at a ratio of $70: 30(\mathrm{v} / \mathrm{v})$; then, elution was performed at a flow rate of $1.0 \mathrm{~mL} / \mathrm{min}$. The volume of sample injection was $20 \mu \mathrm{L}$. The maximum peak area was measured at a wavelength of $280 \mathrm{~nm}$, and the sample concentration was calculated based on the peak area. Caffeine standard was purchased from Sigma-Aldrich (MO, USA).

2.2.2. Chlorogenic Acid Content Analysis. Chlorogenic acid (CGA) content analysis was conducted on the same HPLC instrument and separation column in caffeine content analysis. The mobile phase was composed of (A) 1.5\% acetic acid in water and (B) 100\% methanol, and elution was conducted at a flow rate of $1.0 \mathrm{~mL} / \mathrm{min}$. The volume of sample injection was $20 \mu \mathrm{L}$. The maximum peak area was measured at a wavelength of $320 \mathrm{~nm}$ to determine the sample concentration. CGA standard was obtained from SigmaAldrich. 


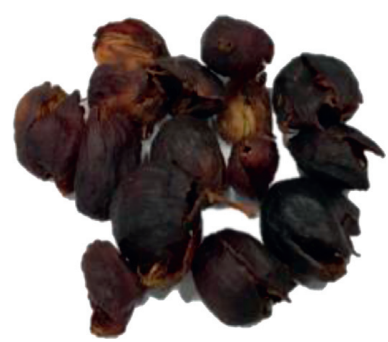

(a)

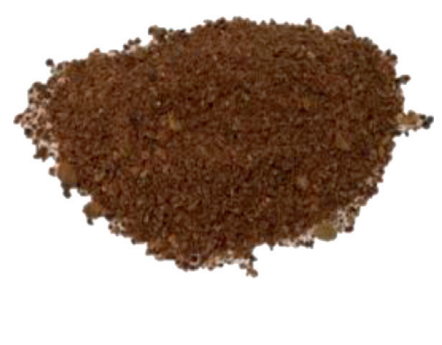

(b)

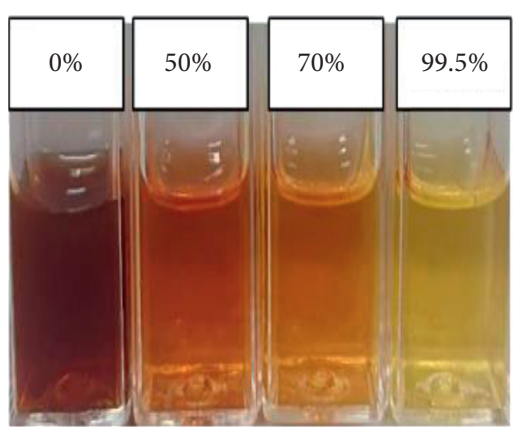

(c)

FIGURE 1: Photograph of (a) coffee pulp; (b) coffee pulp powder; (c) coffee pulp extracts obtained using different ethanol concentrations.

\subsection{Antioxidant Capacity Tests}

2.3.1. Total Phenolic Content Test. A published protocol [31] was employed with some modifications. In brief, $200 \mu \mathrm{L}$ of a $0.5 \mathrm{~N}$ solution of Folin-Ciocalteu phenol reagent was mixed with $200 \mu \mathrm{L}$ of the by-product extract with shaking. The solution was left standing for 5 minutes, and $200 \mu \mathrm{L}$ of $10 \%$ $\mathrm{Na}_{2} \mathrm{CO}_{3}$ was then added; the mixture was evenly shaken through vortexing for 1 minute, and $400 \mu \mathrm{L}$ of deionized water was then added. Subsequently, the reaction was allowed to proceed in the dark for 1 hour at room temperature. After standing for 10 minutes, the mixture was centrifuged at $3000 \mathrm{rpm}$ for 10 minutes, and $200 \mu \mathrm{L}$ of the supernatant was collected to measure the absorbance value at $700 \mathrm{~nm}$. The test was repeated 3 times, and the obtained absorbance value was substituted into the standard curve of the standards to calculate the total phenolic content. In this total phenolic content measurement, gallic acid was used as the standard control.

2.3.2. Total Flavonoid Content Test. The experimental procedure referred to a published protocol [32]. Quercetin was used as the control for the total flavonoid content test. In brief, $50 \mu \mathrm{L}$ of the by-product extract, $50 \mu \mathrm{L}$ of $\mathrm{CH}_{3} \mathrm{OH}$, and $50 \mu \mathrm{L}$ of $5 \% \mathrm{NaNO}_{2}$ were mixed and added to a 96-well microplate. After the microplate was left standing for 5 minutes, $10 \mu \mathrm{L}$ of $10 \% \mathrm{AlCl}_{3}$ was added. After another 6 minutes of standing, $100 \mu \mathrm{L}$ of $1 \mathrm{~N} \mathrm{NaOH}$ was added. After the mixture was left standing for 60 minutes, the absorbance value at $510 \mathrm{~nm}$ was calculated. The test was repeated 3 times. The total flavonoid content was obtained by comparison with the test values of quercetin.

2.3.3. DPPH-Free Radical Scavenging Capacity. The method of the literature [33] was applied with some modifications. The $95 \%$ ethanol solution was evenly mixed with $50 \mu \mathrm{L}$ of the by-product extract of $50 \mu \mathrm{L}$ of $160 \mu \mathrm{M}$ DPPH together, and the solution was allowed to stand in the dark for 30 minutes. The test was repeated 3 times. A spectrophotometer was used to measure the absorbance value at $517 \mathrm{~nm}$. A lower absorbance value indicated that the sample had a superior-free radical scavenging capacity. In this test, vitamin $\mathrm{C}$ was used as the standard, whereas a pure aqueous solution was used as the control.
The DPPH-free radical scavenging capacity was calculated as follows: DPPH-free radical scavenging capacity $(\%)=[1-($ A517 of sample/A517 of blank $)] \times 100 \%$.

2.3.4. ABTS-Free Radical Scavenging Capacity. A published method $[34,35]$ was used to determine the ABTS-free radical scavenging capacity. In brief, $250 \mu \mathrm{L}$ of $7 \mathrm{mM}$ ABTS was evenly mixed with $250 \mu \mathrm{L}$ of $2.45 \mathrm{mM}$ potassium persulfate. The reaction was allowed to proceed in the dark at $4^{\circ} \mathrm{C}$ for 16 hours. Subsequently, 95\% ethanol was added for dilution to set the background absorbance value at $0.7 \pm 0.05$. Then, $180 \mu \mathrm{L}$ of the adjusted solution was added to $20 \mu \mathrm{L}$ of the by-product extract, and the reaction was allowed to proceed in the dark at room temperature for 10 minutes. A spectrophotometer was used to detect the changes in the absorbance value at $734 \mathrm{~nm}$. The test was repeated 3 times. A lower absorbance value indicated a higher inhibition capacity. In the test, Trolox, an antioxidant, was used as the standard to estimate the standard value of the ABTS-free radical scavenging capacity, whereas a pure aqueous solution was used as the control.

The ABTS-free radical scavenging capacity was calculated as follows: ABTS-free radical scavenging capacity $(\%)=[1-($ A734 of sample - A734 of blank $) /($ A734 of control - A734 of blank) $] \times 100 \%$.

2.3.5. Reductive Capacity Test. A published protocol $[36,37]$ was employed with some modifications. In brief, $100 \mu \mathrm{L}$ of $2 \mathrm{mM}$ PBS buffer (pH 6.6), $100 \mu \mathrm{L}$ of $1 \%$ potassium ferricyanide $\left(\mathrm{K}_{3} \mathrm{Fe}(\mathrm{CN})_{6}\right)$, and $100 \mu \mathrm{L}$ of the by-product extract were evenly mixed in a $50^{\circ} \mathrm{C}$ water bath for 20 minutes. After the solution was left standing for cooling for 3 minutes, $100 \mu \mathrm{L}$ of $10 \%$ trichloroacetic acid was added, and the solution was shaken evenly for 1 minute through vortexing. Subsequently, $100 \mu \mathrm{L}$ of the supernatant was added to $100 \mu \mathrm{L}$ of deionized water and $20 \mu \mathrm{L}$ of $0.1 \% \mathrm{FeCl}_{3}$. After the solution was evenly mixed and left standing for 10 minutes, Prussian blue $\left(\mathrm{Fe}_{4}\left[\mathrm{Fe}(\mathrm{CN})_{6}\right]_{3}\right)$ was formed. The test was repeated 3 times. A spectrophotometer was used to detect the changes in the absorbance value at $700 \mathrm{~nm}$. A higher absorbance value implied a higher reductive capacity. In the test, BHA was used as a standard, whereas a pure aqueous solution was used as the control. 
2.4. Tyrosinase Inhibition Capacity Test. The experimental procedure referred to the method of the literature [38]. In the test, $120 \mu \mathrm{L}$ of $5 \mathrm{mM}$ L-Dopa (dissolved in $67 \mathrm{mM}$, pH 6.8 phosphate buffer) and $20 \mu \mathrm{L}$ of the by-product extract were added to a 96-well microplate. Subsequently, $2 \mu \mathrm{L}$ of tyrosinase solution (200 units/reaction) was added, and the solution was evenly mixed at $37^{\circ} \mathrm{C}$ and left to react for 30 minutes. A microplate reader was used to measure the absorbance value at $490 \mathrm{~nm}$. The test was repeated 3 times. Kojic acid at different concentrations was used as the positive control.

The fungal tyrosinase inhibition rate was calculated as follows: fungal tyrosinase inhibition rate $(\%)=(A-B)$ / $A \times 100 \%$, where $A$ is the absorbance value at $490 \mathrm{~nm}$ of the control group and $B$ is the absorbance value at $490 \mathrm{~nm}$ of the sample group.

\section{Results and Discussion}

3.1. Content Analysis through HPLC: Caffeine and CGA Content Analysis. The results of the analysis of the caffeine and CGA content of coffee pulp extracts obtained using different ethanol concentrations are presented in Table 1. The results implied that the caffeine content increased with the decrease in the ethanol concentration. A lower ethanol concentration led to a higher caffeine content; the coffee pulp extract obtained using $0 \%$ ethanol had the highest caffeine content of $0.38 \mathrm{mg} / \mathrm{mL}$. In addition, changes in the CGA content were only observed when the coffee pulp extract was obtained using 50\%-99.5\% ethanol. The CGA content increased with a decline in the ethanol concentration; the coffee pulp extract obtained using 50\% ethanol had the highest CGA content of $0.59 \mathrm{mg} / \mathrm{mL}$. The results are consistent with those of Tran et al. discovering that the CGA content of the coffee pulp extracts obtained using $0 \%, 50 \%$, and $100 \%$ ethanol was $0.04,2.48$, and $0.15 \mathrm{mg} / \mathrm{g} \mathrm{DW}$, respectively [28]. Furthermore, the result of caffeine content in this study is the same as that obtained by Tran et al. The caffeine content of the extract obtained using $0 \%$ ethanol was higher than that of the extract obtained using $100 \%$ ethanol. This study found that the caffeine content increased with a negative correlation with the increase in the ethanol concentration, whereas Tran et al. found that the caffeine content of the extracts obtained using $0 \%, 50 \%$, and $100 \%$ ethanol was $1.16,4.10$, and $0.41 \mathrm{mg} / \mathrm{g}$ DW, respectively [28].

\subsection{Antioxidant Capacity Tests}

3.2.1. Total Phenolic Content Test. The total phenolic content of the coffee pulp extracts obtained using different ethanol concentrations is illustrated in Figure 2. The results indicate that the total phenolic content of the coffee pulp extract obtained using by $50 \%$ ethanol was the highest $(23.16 \mathrm{mg}$ gallic acid/g coffee pulp), followed by that of the extracts obtained using 70\%, 0\%, and 99.5\% ethanol (23.10, 18.14, and $8.65 \mathrm{mg}$ gallic acid/g coffee pulp, respectively). Alkaltham et al. used methanol and ethyl acetate for coffee pulp extraction and revealed that the phenolic content of the coffee pulp extracts obtained using methanol and ethyl acetate was $6.85-7.57$ and $0.183-0.141 \mathrm{mg}$ gallic acid equivalent/dry weigh (GAE/g DW), respectively [26]. Thus, the total phenolic content obtained using ethanol is higher than that of the extracts obtained using methanol and ethyl acetate.

3.2.2. Total Flavonoid Content Test. Figure 3 displays the total flavonoid content of the coffee pulp extracts obtained using different ethanol concentrations. The results showed that the total flavonoid content of the coffee pulp extract obtained using 50\% ethanol was the highest at $25.1 \mathrm{mg}$ quercetin/g coffee pulp), followed by that of the extracts obtained using 70\%, 0\%, and 99.5\% ethanol (20.0, 19.6, and $5.6 \mathrm{mg}$ quercetin/g coffee pulp, respectively). Alkaltham et al. used methanol and ethyl acetate for coffee pulp extraction and discovered that the total flavonoid content of coffee pulp extracts obtained using methanol and ethyl acetate was 8.02 and $0.787 \mathrm{mg}$ catechin equivalent/dry weight (CE/g DW), respectively [26]. However, the standards employed in the present study and by Alkaltham et al. (2020) were different. Therefore, the current authors referred to research on the antioxidant capacity of plants (i.e., Cistus incanus) conducted by Dimcheva and Karsheva in 2018. They applied quercetin and (+)-catechin as standards to measure the total flavonoid content and explored the total flavonoid content during 5-500 minutes of extraction. The results were $40.8-138.44 \mathrm{mg}$ quercetin equivalents/dry weight (QE/g DW) and 6-20.36 mg CE/g DW. Analysis and comparison revealed that during 5-500 minutes of extraction, the $\mathrm{mg} \mathrm{QE/g} \mathrm{DW}$ was 6.8 times higher than $\mathrm{mg} \mathrm{CE} / \mathrm{g} \mathrm{DW}$ [39]. The comparison of the results of Dimcheva and Karsheva (2018) and Alkaltham et al. (2020) indicated that the total flavonoid content of the coffee pulp extraction obtained using methanol and ethyl acetate in the research of Alkaltham et al. (2020) was approximately 55 and $5 \mathrm{mg}$ QE/g DW, respectively. Accordingly, in the total flavonoid content, the total phenolic content of the extract obtained using ethanol was higher than that of the extract obtained using ethyl acetate but lower than methanol.

3.2.3. DPPH-Free Radical Scavenging Capacity Test. The $\mathrm{DPPH}$-free radical scavenging capacity of the coffee pulp extracts obtained using different ethanol concentrations is shown in Figure 4. The results demonstrated that the $\mathrm{IC}_{50}$ of the coffee pulp extract obtained using $50 \%$ ethanol was the lowest $(1.52 \mathrm{mg} / \mathrm{mL})$, followed by that of the extracts obtained using $70 \%, 0 \%$, and $99.5 \%$ ethanol $(1.75,3.96$, and $5.50 \mathrm{mg} / \mathrm{mL}$, respectively). This finding indicated that the coffee pulp extract obtained using 50\% ethanol had the most satisfactory DPPH-free radical scavenging capacity. By contrast, Alkaltham et al. (2020) used methanol for coffee pulp extraction and discovered that the $\mathrm{IC}_{50}$ of the extract obtained using methanol was $5.07-6.01 \mathrm{mg} / \mathrm{mL}$. Accordingly, the $\mathrm{IC}_{50}$ (DPPH-free radical scavenging capacity) of the coffee pulp extract obtained using ethanol is lower than that of the extract obtained using methanol. 
TABle 1: Caffeine and chlorogenic acid content of the coffee pulp extracts obtained using different ethanol concentrations.

\begin{tabular}{lcc}
\hline Ethanol concentrations (\%) & Caffeine $(\mathrm{mg} / \mathrm{mL})$ & Chlorogenic acid $(\mathrm{mg} / \mathrm{mL})$ \\
\hline 0 & 0.38 & 0.002 \\
50 & 0.08 & 0.59 \\
70 & 0.06 & 0.53 \\
99.5 & 0.04 & 0.14 \\
\hline
\end{tabular}

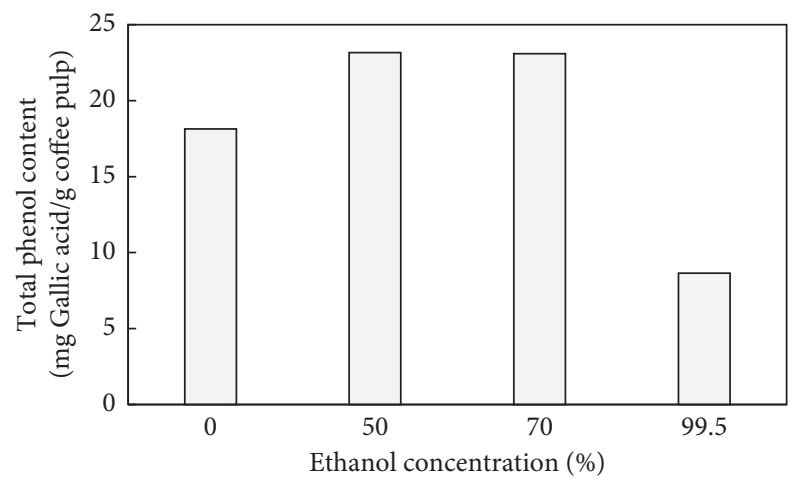

Figure 2: Total phenolic content of the coffee pulp extracts obtained using different ethanol concentrations.

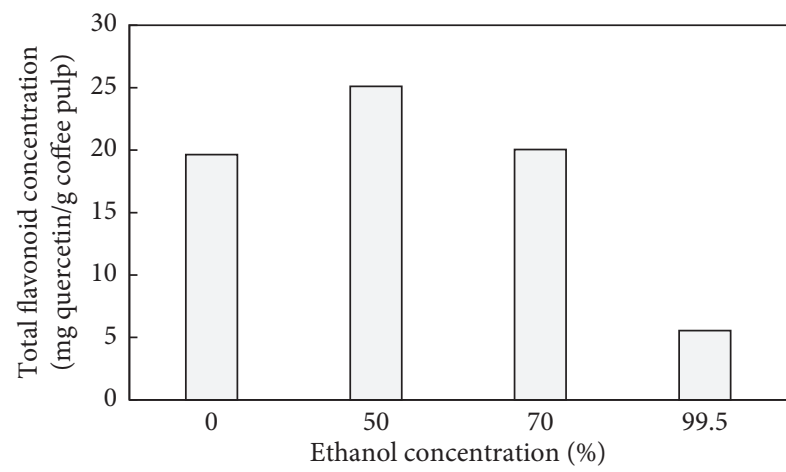

Figure 3: Total flavonoid content of the coffee pulp extracts obtained using different ethanol concentrations.

\subsubsection{ABTS-Free Radical Scavenging Capacity Test.} Figure 5 illustrates the ABTS-free radical scavenging capacity of the coffee pulp extracts obtained using different ethanol concentrations. The results demonstrated that the $\mathrm{IC}_{50}$ of the coffee pulp extract obtained using $50 \%$ ethanol was the lowest $(1.52 \mathrm{mg} / \mathrm{mL})$, followed by that of the extracts obtained using $70 \%, 99.5 \%$, and $0 \%$ ethanol $(1.68,4.51$, and $4.73 \mathrm{mg} / \mathrm{mL}$, respectively). This finding proves that the coffee pulp extract obtained using 50\% ethanol has the most satisfactory ABTS-free radical scavenging capacity. The finding is consistent with that of Tran et al. (2020). They extracted coffee pulp using different solvents and discovered that the ABTS-free radical scavenging capacity of the coffee pulp extract obtained using 50\% ethanol was $50.68 \mathrm{mg}$ TE/g DW, which was higher than that of the extracts obtained using $0 \%$ and $100 \%$ ethanol, and that the extraction effectiveness of $50 \%$ ethanol was superior among different concentrations of methanol and ethanol.
3.2.5. Reductive Capacity Test. Figure 6 displays the reductive capacity of the coffee pulp extracts obtained using different ethanol concentrations. The results showed that the reductive capacity of the coffee pulp extract obtained using $50 \%$ ethanol was the highest ( $41.36 \mathrm{mg} \mathrm{AAE} / \mathrm{g}$ coffee pulp), followed by that of the extracts obtained using $0 \%, 70 \%$, and 99.5\% ethanol $(34.09,28.48$, and $9.20 \mathrm{mg}$ ascorbic acid/g coffee pulp, respectively).

3.3. Tyrosinase Inhibition Capacity Test. The tyrosinase inhibition capacity of the coffee pulp extracts obtained using different ethanol concentrations is illustrated in Figure 7. The results showed that the $\mathrm{IC}_{50}$ of the coffee pulp extract obtained using $70 \%$ ethanol was the lowest $(2.55 \mathrm{mg} / \mathrm{mL})$, and $\mathrm{IC}_{50}$ values of the extracts obtained using $0 \%, 50 \%$, and $99.5 \%$ ethanol were $5.65,2.71$, and $11.16 \mathrm{mg} / \mathrm{mL}$, respectively. Thus, the coffee pulp extract obtained using $70 \%$ ethanol had the most satisfactory tyrosinase inhibition capacity.

According to the literature review, the coffee pulp extract obtained using different solvents has different effects [25]. Compared with the research where the coffee pulp extract was obtained using methanol and ethyl acetate [26], the coffee pulp extract obtained using ethanol had higher total phenolic content and total flavonoid content as well as more satisfactory DPPH-free radical scavenging capacity than that obtained using methanol and ethyl acetate.

In addition, the results of the present study correspond to those of Tran et al. (2020): the coffee pulp extract obtained using 50\% ethanol had superior ABTS-free radical scavenging capacity and higher CGA content than those of the extracts obtained using $0 \%$ and $100 \%$ ethanol [28]. 


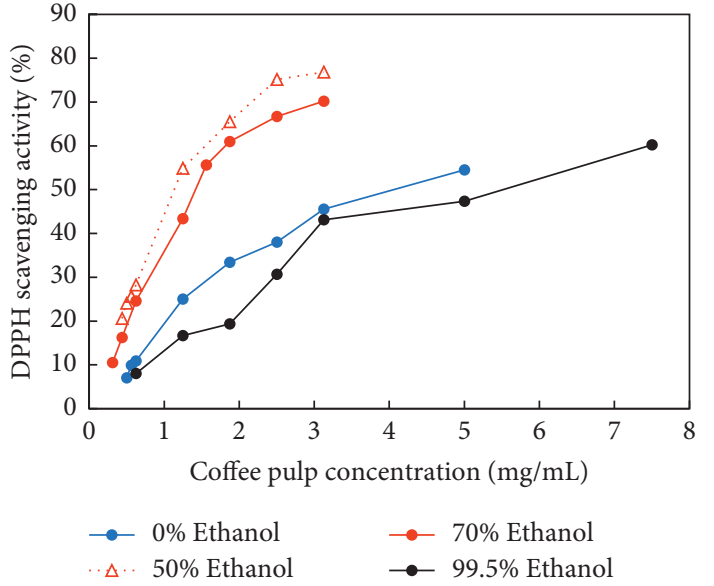

(a)

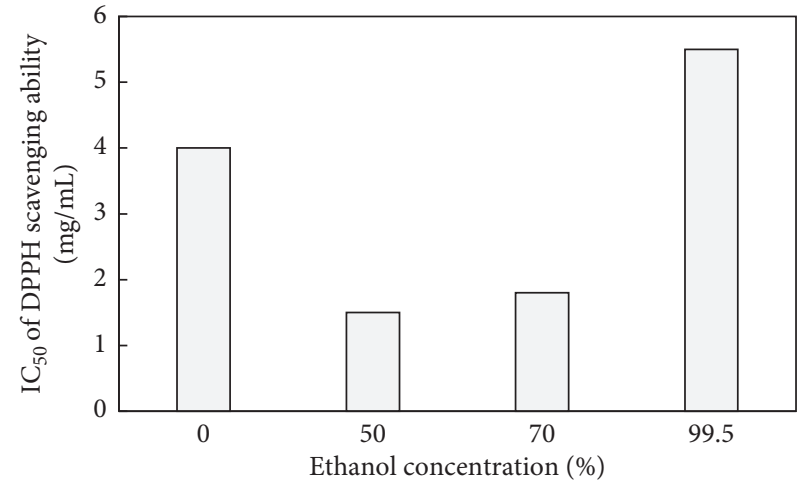

(b)

FIGURE 4: DPPH-free radical scavenging capacity of the coffee pulp extracts obtained using different ethanol concentrations. (a) DPPH-free radical scavenging activity; (b) $\mathrm{IC}_{50}$ of $\mathrm{DPPH}$-free radical scavenging activity.

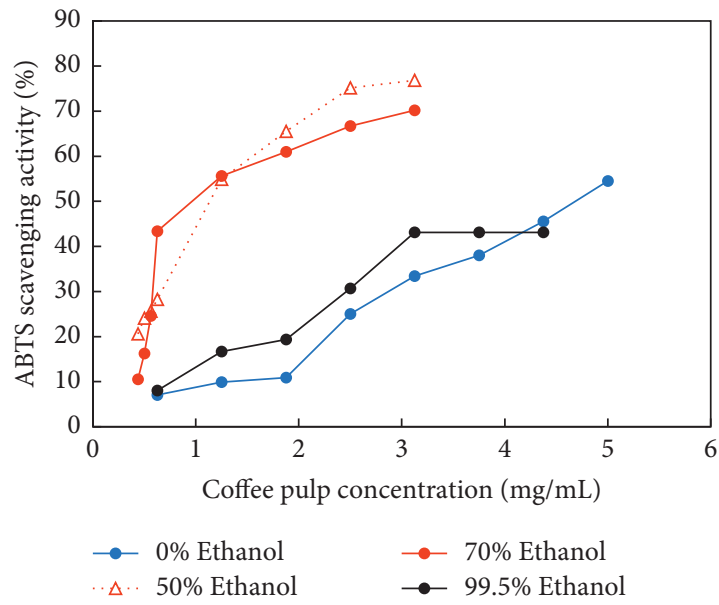

(a)

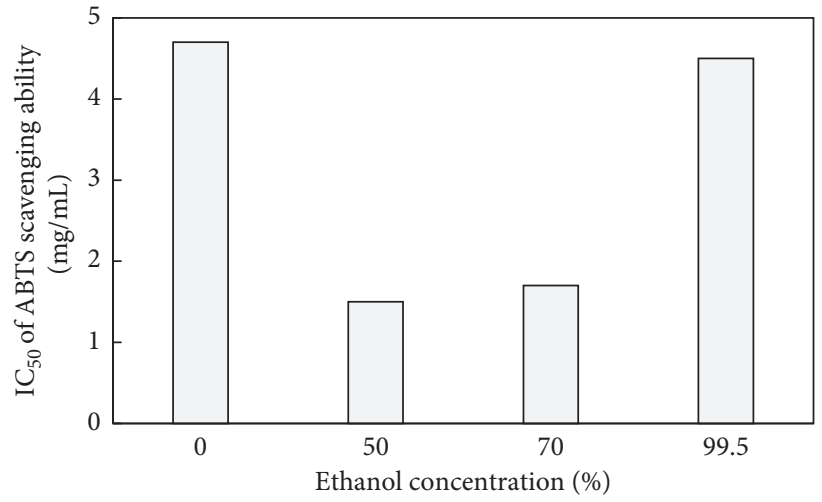

(b)

FIGURE 5: ABTS-free radical scavenging capacity of the coffee pulp extracts obtained using different ethanol concentrations. (a) ABTS-free radical scavenging activity; (b) $\mathrm{IC}_{50}$ of ABTS-free radical scavenging activity.

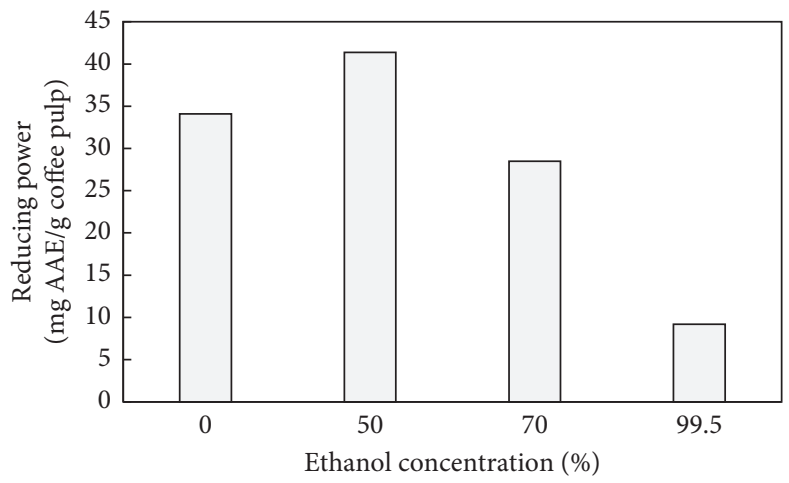

FIGURE 6: Reductive capacity of the coffee pulp extracts obtained using different ethanol concentrations. 


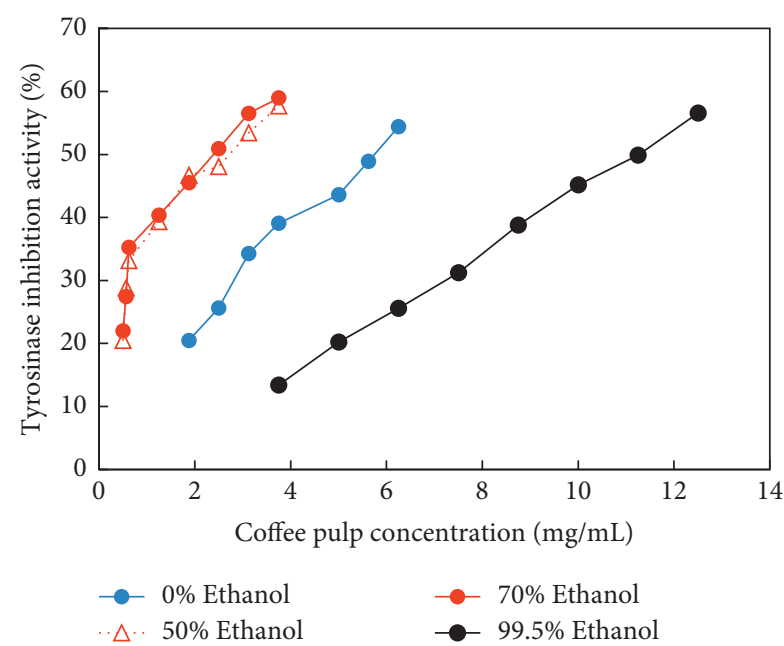

FIgURE 7: Tyrosinase inhibition capacity of the coffee pulp extracts obtained using different ethanol concentrations.

Consistent results for the CGA content and ABTS-free radical scavenging capacity were discovered. Both of the antioxidant capacity decreased in the order of $50 \%, 70 \%$, $99.5 \%$, and $0 \%$ ethanol. Furthermore, the literature indicated the CGA has superior antioxidant capacity and can be effectively applied to the enhancement of DPPH- and ABTS-free radical scavenging capacity [40].

\section{Conclusion}

In this study, different ethanol concentrations were adopted to extract coffee pulp, and the antioxidant capacity and tyrosinase inhibition capacity were examined. The results revealed that the coffee pulp extract obtained using $70 \%$ ethanol had the highest tyrosinase inhibition capacity, whereas that obtained using 50\% ethanol had the most satisfactory antioxidant capacity (total phenolic content, total flavonoid content, DPPH-free radical scavenging capacity, and ABTS-free radical scavenging capacity). Accordingly, although the coffee pulp extracts obtained using different ethanol concentrations had varying antioxidant capacities, they all had antioxidant effects. The use of different ethanol concentrations greatly affected the tyrosinase inhibition capacity.

\section{Data Availability}

The data used to support the findings of this study are included within the article.

\section{Conflicts of Interest}

None of the authors have any professional or financial conflicts of interest.

\section{Acknowledgments}

This study was supported by Ministry of Science and Technology (grant number 110-2622-E-239-003).

\section{References}

[1] J. Czachor, M. Miłek, S. Galiniak, K. Stępień, M. Dżugan, and M. Mołoń, "Coffee extends yeast chronological lifespan through antioxidant properties," International Journal of Molecular Sciences, vol. 21, no. 24, p. 9510, 2020.

[2] A. E. Atabani, A. a. H. Al-Muhtaseb, G. Kumar, G. D. Saratale, M. Aslam, and H. A. Khan, "Valorization of spent coffee grounds into biofuels and value-added products: pathway towards integrated bio-refinery," Fuel, vol. 254, Article ID 115640, 2019.

[3] E. K. J. Pauwels and D. Volterrani, "Coffee consumption and cancer risk: an assessment of the health implications based on recent knowledge," Medical Principles and Practice, vol. 30, no. 5, pp. 401-411, 2021.

[4] P. S. Murthy and M. Madhava Naidu, "Sustainable management of coffee industry by-products and value addition-a review," Resources, Conservation and Recycling, vol. 66, pp. 45-58, 2012.

[5] A. A. I. Ratnadewi, H. Masruroh, Suwardiyanto, and A. B. Santoso, "Application of coffee peel waste as raw material for xylooligosaccharide production," Coffee Science, vol. 14, no. 4, pp. 446-454, 2019.

[6] International Coffee Organization, "Total production by all exporting countries," Historical Data on the Global Coffee Trade 2020: Total Production, International Coffee Organization, London, UK, 2020.

[7] S. Ponte, “The 'latte revolution'? regulation, markets and consumption in the global coffee chain," World Development, vol. 30, no. 7, pp. 1099-1122, 2002.

[8] W. Dong, D. Wang, R. Hu, Y. Long, and L. Lv, "Chemical composition, structural and functional properties of soluble dietary fiber obtained from coffee peel using different extraction methods," Food Research International, vol. 136, Article ID 109497, 2020.

[9] M. Daglia, A. Papetti, C. Gregotti, F. Bertè, and G. Gazzani, "In vitro antioxidant and ex vivo protective activities of green and roasted coffee," Journal of Agricultural and Food Chemistry, vol. 48, no. 5, pp. 1449-1454, 2000.

[10] S. I. Mussatto, E. M. S. Machado, S. Martins, and J. A. Teixeira, "Production, composition, and application of coffee and its industrial residues," Food and Bioprocess Technology, vol. 4, no. 5, pp. 661-672 2011.

[11] L. S. Oliveira and A. S. Franca, "An overview of the potential uses for coffee husks," in Coffee in Health and Disease Prevention, V. R. Preedy, Ed., Academic Press, London, UK, pp. 283-291, 2015

[12] P. Esquivel and V. M. Jiménez, "Functional properties of coffee and coffee by-products," Food Research International, vol. 46, pp. 488-495, 2012.

[13] P. S. Murthy and M. Madhava Naidu, "Recovery of phenolic antioxidants and functional compounds from coffee industry by-products," Food and Bioprocess Technology, vol. 5, pp. 897-903, 2012

[14] P. D. Fitria, M. Amin, W. P. Lokapirnasari, and M. Lamid, "Supplementation of fermented coffee-peel flour to increase high-density lipoprotein (HDL) cholesterol, docosahexaenoic acids (DHA) and eicosapentaenoic acids (EPA) deposition in tilapia fillet," Biocatal Agric Biotechnol, vol. 24, Article ID 101502, 2020.

[15] A. A. I. Ratnadewi, M. H. A. Zain, A. Kusuma, W. Handayani, A. S. Nugraha, and T. A. Siswoyo, "Lactobacillus casei fermentation towards xylooligosaccharide (XOS) obtained from coffee peel enzymatic hydrolysate," Biocatal Agric Biotechnol, vol. 23, Article ID 101446, 2020. 
[16] E. D. D. Castro, L. S. Villela, L. M. Mendes, R. F. Mendes, A. G. C. Ribeiro, and J. B. Guimarães Junior, "Analysis of the coffee peel application over the soil-cement bricks properties," Coffee Science, vol. 14, no. 1, pp. 12-23, 2019.

[17] R. S. Reis, L. G. P. Tienne, D. D. H. S. Souza, M. D. F. V. Marques, and S. N. Monteiro, "Characterization of coffee parchment and innovative steam explosion treatment to obtain microfibrillated cellulose as potential composite reinforcement," Journal of Materials Research and Technology, vol. 9, no. 4, pp. 9412-9421, 2020.

[18] M. Zarantoniello, A. Zimbelli, B. Randazzo, M. D. Compagni, C. Truzzi, and M. Antonucci, "Black Soldier Fly (Hermetia illucens) reared on roasted coffee by-product and Schizochytrium sp. as a sustainable terrestrial ingredient for aquafeeds production," Aquaculture, vol. 518, Article ID 734659, 2020.

[19] I. K. da Silva Correia, P. F. Santos, C. S. Santana, J. B. Neris, F. H. M. Luzardo, and F. Velasco, "Application of coconut shell, banana peel, spent coffee grounds, eucalyptus bark, piassava (Attalea funifera) and water hyacinth (Eichornia crassipes) in the adsorption of $\mathrm{Pb} 2+$ and $\mathrm{Ni} 2+$ ions in water," Journal of Environmental Chemical Engineering, vol. 6, pp. 2319-2334, 2018.

[20] T. H. Tran, A. H. Le, T. H. Pham, D. T. Nguyen, S. W. Chang, and W. J. Chung, "Adsorption isotherms and kinetic modeling of methylene blue dye onto a carbonaceous hydrochar adsorbent derived from coffee husk waste," The Science of the Total Environment, vol. 725, Article ID 138325, 2020.

[21] I. Gulcin, "Antioxidants and antioxidant methods: an updated overview," Archives of Toxicology, vol. 94, pp. 651-715, 2020.

[22] A. Barbulova, G. Colucci, and F. Apone, "New trends in cosmetics: by-products of plant origin and their potential use as cosmetic active ingredients," Cosmetics, vol. 2, pp. 82-92, 2015.

[23] C. T. Wu, D. C. Agrawal, W. Y. Huang, H. C. Hsu, S. J. Yang, and S. L. Huang, "Functionality analysis of spent coffee ground extracts obtained by the hydrothermal method," Journal of Chemistry, vol. 2019, Article ID 4671438, 13 pages, 2019.

[24] M. A. Arellano-González, M. A. Ramírez-Coronel, M. T. Torres-Mancera, G. G. Pérez-Morales, and G. SaucedoCastañeda, "Antioxidant activity of fermented and nonfermented coffee (Coffea arabica) pulp extracts," Food Technology and Biotechnology, vol. 49, no. 3, pp. 374-378, 2011.

[25] M. Geremu, Y. B. Tola, and A. Sualeh, "Extraction and determination of total polyphenols and antioxidant capacity of red coffee (Coffea arabica L.) pulp of wet processing plants," Chemical and Biological Technologies in Agriculture, vol. 3, p. 25, 2016.

[26] M. S. Alkaltham, A. Salamatullah, and K. Hayat, "Determination of coffee fruit antioxidants cultivated in Saudi Arabia under different drying conditions," Journal of Food Measurement and Characterization, vol. 14, pp. 1306-1313, 2020.

[27] T. M. K. Tran, T. Akanbi, T. Kirkman, M. H. Nguyen, and Q. V. Vuong, "Optimal aqueous extraction conditions as a green technique for recovery of phenolic antioxidants from Robusta dried coffee pulp," European Journal of Engineering Research and Science, vol. 5, pp. 1069-1074, 2020.

[28] T. M. K. Tran, T. Kirkman, M. Nguyen, and Q. V. Vuong, "Effects of drying on physical properties, phenolic compounds and antioxidant capacity of Robusta wet coffee pulp (Coffea canephora)," Heliyon, vol. 6, Article ID e04498, 2020.
[29] S. R. Delgado, A. F. A. Arbelaez, and B. Rojano, "Antioxidant capacity, bioactive compounds in coffee pulp and implementation in the production of infusions," Acta Sci PolonTechnol Aliment, vol. 18, no. 3, pp. 235-248, 2019.

[30] A. A. Aly, M. A. Kassem, and A. S. Amin, "Determination of caffeine in roasted and irradiated coffee beans with gamma rays by high performance liquid chromatograph," Food Science and Quality Management, vol. 22, pp. 28-34, 2013.

[31] M. Y. Chang, Y. Y. Lin, Y. C. Chang, W. Y. Huang, W. S. Lin, and C. Y. Chen, "Effects of infusion and storage on antioxidant activity and total phenolic content of black tea," Applied Sciences, vol. 10, no. 8, p. 2685, 2020.

[32] Y. S. Lin, W. S. Lin, J. W. Tung, Y. C. Cheng, M. Y. Chang, and C. Y. Chen, "Antioxidant capacities of jujube fruit seeds and peel pulp," Applied Sciences, vol. 10, no. 17, p. 6007, 2020.

[33] S. L. Huang, W. H. Wang, X. Y. Zhong, C. T. Lin, W. S. Lin, and M. Y. Chang, "Antioxidant properties of Jatropha curcas L. seed shell and kernel extracts," Applied Sciences, vol. 10, no. 9 , p. 3279, 2020.

[34] W. Y. Huang, P. C. Lee, J. C. Hsu, Y. R. Lin, H. J. Chen, and Y.S. Lin, "Effects of water quality on dissolution of yerba mate extract powders," Science World Journal, vol. 2014, Article ID 768742, 12 pages, 2014.

[35] C. F. Chan, C. T. Wu, W. Y. Huang, W. S. Lin, H. W. Wu, and T. K. Huang, "Antioxidation and melanogenesis inhibition of various Dendrobium tosaense extracts," Molecules, vol. 23, no. 7, p. 1810, 2018.

[36] W. Y. Huang, Y. R. Lin, R. F. Ho, H. Y. Liu, and Y. S. Lin, "Effects of water solutions on extracting green tea leaves," Science World Journal, vol. 2013, Article ID 368350, 6 pages, 2013.

[37] Y. S. Lin, W. Y. Huang, P. Y. Ho, S. Y. Hu, Y. Y. Lin, and C. Y. Chen, "Effects of storage time and temperature on antioxidants in juice from Momordica charantia L. and Momordica charantia L. var. abbreviata," Ser. Molecules, vol. 25 , no. 16 , p. $3614,2020$.

[38] C. C. Tsai, C. F. Chan, W. Y. Huang, J. S. Lin, P. Chan, and H. Y. Liu, "Applications of Lactobacillus rhamnosus spent culture supernatant in cosmetic antioxidation, whitening and moisture retention applications," Molecules, vol. 18, no. 11, pp. 14161-14171, 2013.

[39] V. Dimcheva and M. Karsheva, "Cistus incanus from Strandja mountain as a source of bioactive antioxidants," Plants, vol. 7, p. 8, 2018.

[40] S. Wang, Y. Li, X. Meng, S. Chen, D. Huang, and Y. Xia, "Antioxidant activities of chlorogenic acid derivatives with different acyl donor chain lengths and their stabilities during in vitro simulated gastrointestinal digestion," Food Chemistry, vol. 357, Article ID 129904, 2021. 